\title{
Acoustic playback experiments to study behavioral responses of free-ranging marine animals to anthropogenic sound
}

\author{
Peter Tyack* \\ Biology Department, Woods Hole Oceanographic Institution, Woods Hole, Massachusetts 02543, USA
}

\begin{abstract}
Growing concern about the effects of anthropogenic sound on marine life has highlighted the need for empirical methods to study behavioral responses of marine animals to specific acoustic exposures. Some effects have been discovered by observing coincidence of effects with sound exposure, e.g. beaked whales such as Ziphius cavirostris and Mesoplodon densirostris may mass strand during sonar exercises. Sometimes new activities trigger precautionary concern, such as the potential effects of deep water seismic surveys on deep-diving endangered species, e.g. sperm whales Physeter macrocephalus. In both cases, the best way to prove that a particular sound stimulus causes a behavioral response involves experiments whereby a specific dose of sound is broadcast to an animal and the acoustic exposure and behavioral responses of the animal are measured. The present paper argues for a balance of experimental and observational studies of effects of sound on marine life, designed so that each kind of study complements the other.
\end{abstract}

KEY WORDS: Effects of sound · Marine mammals · Playback experiments

\section{INTRODUCTION}

Ethologists and behavioral ecologists aim to study the behavior of animals in the natural settings in which the behavior of interest evolved. This often means that their observations occur in a rich and complex network of stimuli and behavioral contexts. When a field worker observes a possible link between a signal or stimulus and a behavioral response, without new experiments, it is seldom possible to demonstrate that the signal actually caused the response. The earliest such experiments tended to use visual stimuli, such as the classic studies of how insects use visual landmarks for homing (Tinbergen \& Kruyt 1938) or the attributes of shape and motion required to trigger an anti-predator response in young waterfowl (Lorenz 1939, Tinbergen 1948).

For millennia, hunters and naturalists have known how to call-in wild animals by imitating calls, but it was not until the invention of the gramophone that scientists were able to study responses of animals to the playback of sound recordings. Soon after the gramophone was invented, Garner (1892) conducted play- backs to rhesus monkeys, but it was not until technical advances in audio electronics after World War II (WWII) that biologists started to develop experimental methods for playing back electronic reproductions of acoustic stimuli to test for responses. As with the early ethological experiments, some of these early playback experiments involved anti-predator behavior. For example, Roeder (1962) showed that moths in the wild had several different responses to playback of echolocation clicks from bats, from avoidance of distant clicks to unpredictable diving movements to escape from near ones. Other experiments focused on social communication between conspecifics such as responses of territorial songbirds to playback of song (Weeden \& Falls 1959).

Playback experiments with marine animals have lagged behind work with terrestrial animals. Many fishers recognize that fish have sensitive hearing, but biologists did not even recognize that fish could hear until the early work of von Frisch (1938). While some whalers knew that male humpback whales Megaptera novaeangliae sing (Best 2008), marine scientists only 
started publishing about the underwater sounds and hearing of marine mammals after WWII (Schevill \& Lawrence 1949). Research on ocean acoustics during and after WWII highlighted how favorable the ocean is for long-range sound propagation. While light can only travel a few hundreds of meters under the best ocean conditions, low frequency sound can travel hundreds of kilometers in the deep ocean (Urick 1983). The importance of sound as a distance sense is shown by the discovery that toothed whales use sound as a biosonar to echolocate prey, the seafloor, and the sea surface (Au 1993). Deep-diving animals such as sperm whales Physeter macrocephalus can detect the seafloor (Madsen et al. 2005) or surface (Zimmer et al. 2005) at ranges of hundreds of meters, well beyond visual range, and beaked whales Mesoplodon densirostris use echolocation to find and capture deep prey (Johnson et al. 2004, Madsen et al. 2005). Baleen whales make low frequency calls that are sometimes detectable at ranges of hundreds of kilometers (Spiesberger \& Fristrup 1990). While most marine fish and mammal species have good vision, it is now generally accepted that sound is a critical distance sense for most species. The 1960s saw path-breaking playback experiments with marine fish (Winn et al. 1964), and the first playback experiments with wild whales began in the 1970s and 1980s (Cummings \& Thompson 1971, Fish \& Vania 1971, Clark \& Clark 1980, Tyack 1983).

\section{METHODS TO STUDY EFFECTS OF ANTHROPOGENIC SOUND ON MARINE LIFE}

There has been growing recognition over the past $40 \mathrm{yr}$ that anthropogenic sound may affect the behavior and physiology of wildlife. The first papers raising concern about the impact of underwater noise on marine animals noted that propulsion noise from ships elevates ambient noise in many marine environments. Soon after it was discovered that whales produce low frequency calls suitable for long-range communication, Payne \& Webb (1971) suggested that shipping noise could mask these whale calls, significantly reducing the range over which whales could communicate. Myrberg $(1978,1980)$ similarly noted that the range over which marine fish communicate could be greatly reduced by environmental noise, including shipping. We know that calls of fish and whales are used for critical functions such as locating and selecting a mate (Tyack 1998). Many populations of whales (Roman \& Palumbi 2003) and fish (Pauly et al. 1998) have been decimated by commercial whaling and fishing. This reduction of population may increase the separation between animals at the same time that noise may reduce the range of communication. There is good reason for concern that compounding of these effects could affect the ability of these populations to recover (Tyack 2008).

\section{Controlled exposure experiments}

Concerns about defining the effects of anthropogenic sounds suggest an important application of playback techniques involving experiments designed to test how and when anthropogenic sounds may alter the behavior of animals. Many features of these applied playback experiments, called controlled exposure experiments (CEE; Tyack et al. 2003), are the same as those for traditional ethological playbacks. For example, even if the primary experimental stimulus for a playback is a natural communication sound, control stimuli often include artificial anthropogenic sounds. CEEs most differ from standard playbacks in that they are usually designed to control and measure the parameters of acoustic exposure much more precisely than is typical for playbacks. The experimenter for a traditional playback experiment typically starts by informally manipulating many features of the playback (e.g. loudness of the stimulus, behavioral context of the subject, range to the subject) until the playback 'works', i.e. elicits a response. Then the formal work of the experiment involves playing control stimuli in the same setting to test for differential response. While there has been great attention to details of experimental design in playback experiments (McGregor 1992, Kroodsma et al. 2001), there has been considerably less explicit focus on quantifying the acoustic parameters of the stimuli. In the case of a CEE, the experimenter must be much more careful and explicit about how s/he presents the stimulus and more careful about measuring exposure at the animal, in order to be able to derive a function relating behavioral response to acoustic exposure. It has turned out to be extremely useful to attach a sound recording tag to CEE subjects in order to measure the stimulus precisely as received by the animal (Johnson \& Tyack 2003). However, knowledge of hearing is also required to actually understand the stimulus as perceived by the subject. Here I will use the word stimulus for a sound that the subject might be able to perceive, retaining 'signal' for more general usage.

\section{How important is increased masking of hearing caused by anthropogenic noise?}

Even though the first papers on the effects of anthropogenic sound on wildlife raised concerns about masking, and even though masking of sound is well under- 
stood for hearing in many species, no studies have tested how noise changes the effective range of communication in wildlife in their natural environment. In practice it is very difficult to identify when an animal misses an opportunity to detect a call because of elevated noise, particularly in observational studies, but one can imagine an experimental design that could evaluate responses of subjects in the wild to communication calls as a function of experimentally manipulated noise or natural variations in noise. An important element of such a design would involve finding a situation where the subject is almost certain to make a detectable response if it detects the signal. Hundreds of masking studies investigate responses of laboratory animals to artificial signals in experimentally manipulated noise, but few such studies use natural calls in the wild. Nor has research demonstrated the maximum ranges over which animals need to communicate. For example, while whale songs used for reproductive advertisement are sometimes detectable at ranges of hundreds of kilometers (Spiesberger \& Fristrup 1990), we do not know from how far away females actually monitor a male when selecting a mate. These remain important areas for future experimental work. One experimental protocol that offers promise for evaluating these questions involves playback of calls to increase the probability of detecting animals during acoustic surveys (Gibbs \& Melvin 1993, Allen et al. 2004). These experiments quantify the number of detections of responses to playback as a function of range from the speaker to the animal that responded. If these surveys measured acoustic parameters and were able to link variation in ambient noise to variation in the distribution of ranges and received levels at which animals responded to playback, this kind of design might be able to address variation in response to calls as a function of variation in ambient noise.

While we know little about whether current levels of ambient noise inhibit important communication in wild animals, recent research has demonstrated that animals have evolved abilities to compensate for noise. These mechanisms for increasing the detectability of signals include waiting to call until noise decreases, increasing the rate of calling, increasing signal intensity, increasing signal duration, and shifting signal frequency outside of the noise band (Tyack 2008). Many of these changes are thought to impose a cost on the animal, for example by increasing the energetic cost of calling. The cost of compensation suggests that anthropogenic noise has interfered with an important enough function that the animal is willing to undergo this cost to compensate for the disruptive effects of noise. Studies on mechanisms to compensate for noise include a variety of methods involving observational and experimental studies in the laboratory and in the wild. For studies that attempt to understand the ecological significance of disruption of behavior, it is important to use an ecologically valid setting and to specify the context. For understanding basic sensory mechanisms, there is less concern about ecological validity or context-specificity of responses than for behavioral ecological studies of whether anthropogenic noise hinders animals from achieving the goals of their behaviors. It is particularly important to sample wild animals when interpreting the effect of specific disruptions of behavior on the animal's ability to grow, reproduce, and survive. For sensory studies of compensation for masking, the combination of different methods often strengthens interpretation, and investigators are relatively free to select the easiest kind of study to perform. However, studying the behavioral ecological impact of noise demands careful thought about appropriate contexts and time scales for study. In general, studies of wild animals in their natural environment will involve fewer questions about ecological validity than studies of animals in captivity that are well fed and protected from disease and predation. For research on effects of sound on wild animals, researchers should be aware that the vulnerability of animals to disruption may vary with site and season (McEwen \& Wingfield 2003).

\section{Avoidance reactions to noise}

The initial concerns about effects of noise focused on chronic effects of long-term exposure to elevated ambient levels of noise from sources such as ship propulsion, which is ubiquitous. Yet most of the approaches to studying effects of noise on wildlife involve shortterm acute responses to discrete exposures to specific transient sounds. Practical and ethical issues favor observational studies over experimental approaches to study chronic effects of very long-term exposures to noise. Long-term observational studies have raised concern that vessel noise may degrade the quality of marine mammal habitat. For example, Bryant et al. (1984) combined results from a series of censuses of gray whales Eschrichtius robustus from 1952 to 1982 to suggest that gray whales abandoned one of their primary breeding lagoons in Baja California, Mexico for about a decade while dredging and shipping was present in the lagoon. Bejder et al. (2006) studied dolphin abundance in an area where dolphin watching has been growing for over about 2 decades, and suggested that their results uncover a long-term shift in habitat use caused by vessel traffic. Morton \& Symonds (2002) showed that killer whales Orcinus orca avoided an important part of their habitat from 1993 to 1999 when fish farms installed acoustic harassment devices, which are designed to deter marine mammals from predating 
on farmed fish. In a shorter-term study over 2 summers, Allen \& Read (2000) showed that dolphins change their usage of foraging habitats on weekends when vessel traffic is heavy compared to on weekdays. The interpretation that the vessels actually caused these responses is supported by short-term studies evaluating the responses of animals to controlled vessel approaches (e.g. Janik \& Thompson 1996). One problem with these observational studies is that it can be difficult to test whether the animals are responding to the noise per se, or whether the noise indicates the presence of human activity, which the animals may avoid because of hazards such as collision or pollution. However, few would suggest attempting the experimental introduction of noise on the scales studied by Bryant et al. (1984) and Bejder et al. (2006). As long as any association of noise with other hazards is reliable, and the noise elicits the response, the question of whether a sound is inherently aversive or causes avoidance because it is associated with other aversive experiences may not make much of a practical difference.

Long-term observations of effects, such as avoidance reactions over medium scales of habitat, are particularly well suited to documenting the changes to a population. However, one must wait until after the population effect has occurred in order to know what happened. We know so little about most marine mammal populations that, once a change has been detected, it may be too late for effective conservation efforts (Taylor \& Gerrodette 1993, Taylor 1995). For many threatened or endangered species and critical habitats, methods that can identify problems earlier are preferable. Where precautionary approaches are followed, studies of impact may be requested before a new sound source is actually made operational. There can also be difficulties in identifying whether sound was the critical factor in changes in distribution or behavior. Compared to cases where sound is known to have caused disturbance, there are more cases where species have ceased using a habitat after coastal development for which we simply cannot tease apart whether sound played a critical role compared to visual stimuli, physical disturbance of habitat, pollution, etc. As discussed above, developing a variety of study designs working at different temporal and spatial scales will often be preferable to testing for effects at just one scale. In general, it may be easier to detect short-term responses to specific stimuli, but harder to interpret their consequences, and easier to interpret the consequences of large-scale effects on populations, but more difficult to detect them and relate them to quantified exposure. An integrated program of research involving both scales can optimize the strengths of each approach. It can be particularly powerful to combine long-term observational studies to document population-level effects on ecological scales with shorter term experimental studies of behavioral responses of individual animals to specific acoustic exposures. For example, Richardson et al. (1986) observed responses of feeding bowhead whales Balaena mysticetus to sounds of commercial seismic surveys and from controlled exposures to a single airgun. In general, avoidance reactions were observed when these whales were exposed to levels above $\sim 160 \mathrm{~dB}$ re $1 \mu \mathrm{Pa}$, whether from an array of airguns in an actual survey or from a controlled exposure to a single airgun.

\section{Risks from acute reactions to sound}

In the United States, the conduct of playback experiments with marine mammals is regulated with permits that define all playbacks as intrusive. Intrusive research is defined by the permitting agency as 'any procedure conducted for bona fide scientific research that involves:

- a break in or cutting of the skin or equivalent,

- insertion of an instrument or material into an orifice,

- introduction of a substance or object into the animal's immediate environment that is likely either to be ingested or to contact and directly affect animal tissues (i.e. chemical substances), or

- a stimulus directed at animals that may involve a risk to health or welfare or that may have an impact on normal function or behavior (e.g. audio broadcasts directed at animals that may affect behavior or attachment of instruments to an animal using suction-cups or by penetration of the animal's skin)' $\underline{\mathbf{1}}$.

This attempt by the regulator to establish equivalence between invasive surgery and playback of any sound to an animal seems questionable if the goal is to equate risks. Many of the sounds that could be tested in playbacks, such as the propulsion sounds of ships, are completely unregulated. This leads to the perverse outcome that the agency responsible for protecting animals restricts research into the effects of otherwise unregulated activities. If the agency supported research critical to understanding why animals respond to particular stimuli in a way that poses a risk, this would support steady improvements in mitigation. On the other hand, if critical research is restricted with a much more precautionary approach than is applied to the ubiquitous stimuli that may threaten marine mammals, then the animals are more at risk and managers will continue to be surprised by unexpected problems.

\footnotetext{
${ }^{1}$ National Marine Fisheries Service, Office of Protected Resources Glossary. Available at: www.nmfs.noaa.gov/pr/ glossary.htm
} 
There are some cases where observational studies provide strong evidence for severe, even lethal, effects of sound over short time periods. Low-flying aircraft have been documented to cause stampedes of walrus at haulouts with some animals being crushed and killed (Richardson et al. 1995), but the overflights are visible as well as audible and it is not certain how important the sound of the overflight is in stimulating the stampede. There are also several cases where atypical mass strandings of beaked whales, including Ziphius cavirostris and Mesoplodon densirostris have coincided with naval sonar exercises. These strandings are atypical because several different whales or groups of whales strand over tens of kilometers within a few hours. The scale of the strandings is consistent with acoustic propagation in the sea (Frantzis 1998). This kind of atypical beaked whale stranding was not reported before the early 1960s when the current midfrequency sonars (AN-SQS26 and the later 53) were introduced by the United States Navy (Friedman 1989). Since then there have been about a dozen atypical strandings reported to coincide with naval exercises (Cox et al. 2006). The number of coincidences between strandings and sonar makes a convincing case for some sort of connection (Cox et al. 2006). However, it is not known where the stranded whales were when they first responded to the sonar, so it is not possible to estimate the sound exposure responsible for the strandings. Most navies use a variety of sound sources during sonar exercises and do not disclose all of the information on their sonars, or on the areas or times of sonar operation, so it is difficult for independent observers to monitor exercises or even to identify which sounds were involved in a stranding. It is nearly impossible to collect data on sonar usage and strandings adequate for a proper correlation analysis. Of the dozen or more cases of beaked whale strandings coincident with naval exercises, information about what sounds were transmitted has been published for only 2 of the incidents (D'Amico 1998, Evans \& England 2001). In addition to the relatively strong link between atypical mass strandings of beaked whales with naval sonar exercises, there are also reports of beaked whales stranding during exposure to other intense sound sources such as airguns (Malakoff 2002), and of strandings of other species coinciding with naval exercises (Hohn et al. 2006, Southall et al. 2006). It is very difficult on a case-by-case basis to test whether these rarely reported associations are caused by the sound or are coincidental. There are simply not enough data to define whether beaked whales are more at risk from sonar than other sounds of equal intensity, nor whether other species are at lower risk than beaked whales.

These problems indicate the need for several additional sources of information about the effects of sonar on whales. One approach would be to measure sound exposures and behavior of whales during actual sonar exercises. This approach would allow estimation of the the spatial extent of effects from actual exercises on different species. However, since the range of potential outcomes of the responses observed includes lethal stranding, involvement in this kind of study raises ethical and regulatory issues that are less of a concern for a more controlled playback where it is much less plausible that the subject would be harmed. Unlike concerns about long-term effects of chronic exposure on populations, the time scale of the sonar-related strandings only involves a few hours. This time scale is relatively well suited to playback experiments, but any playback in this setting must be designed very conservatively to reduce the risk of harm to the subjects or any other animals nearby. This kind of experiment is particularly well suited to defining the precise acoustic properties of stimuli that elicit the early, hopefully safe, components of a behavioral reaction that in the end may pose a risk of stranding.

For a beaked whale to strand, it must swim far from its deep-water habitat. This means that an initial part
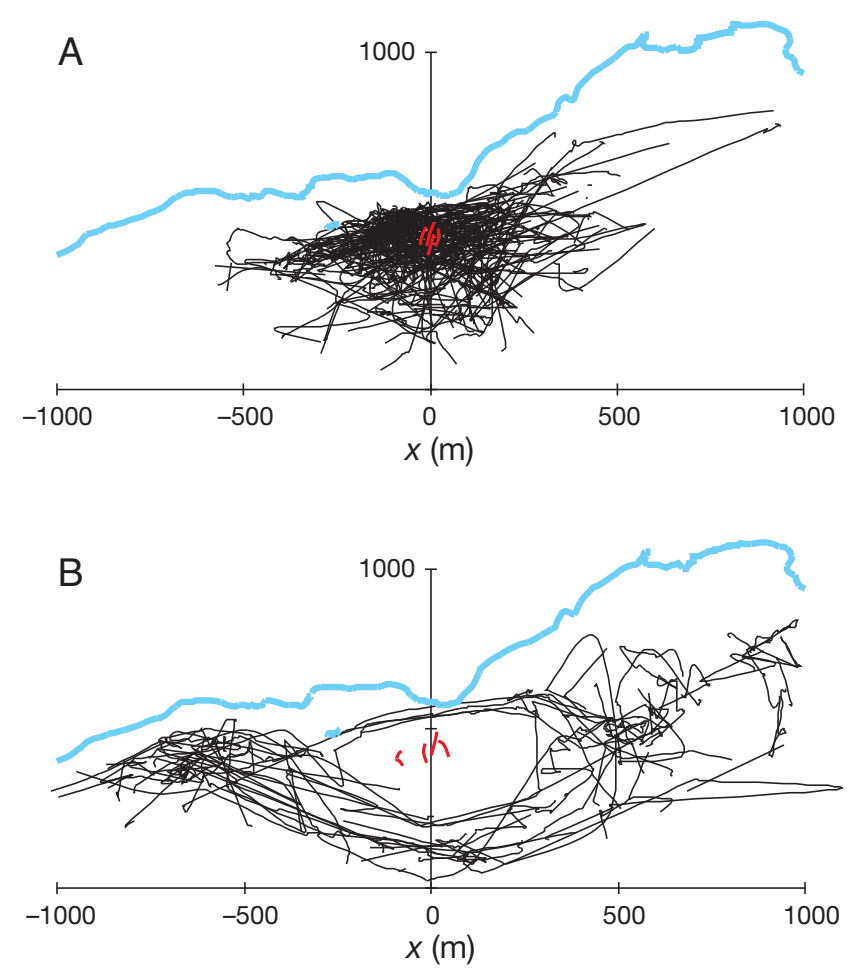

Fig. 1. Phocoena phocoena. Tracks of harbor porpoise groups monitored (A) in control conditions and (B) when exposed to a pinger transmitting at a source level of $145 \mathrm{~dB}$ re $1 \mu \mathrm{Pa}$. The blue line indicates land; the red lines indicate float lines from which the pinger was suspended. There is an obvious gap in the distribution of porpoises near the pingers in (B), indicating avoidance reactions of several hundred meters (from Culik et al. 2001) 
of the response to sonar must involve an avoidance response. A set of observations of strong avoidance reactions of porpoises to anthropogenic sounds led to a series of experiments that suggest that porpoises may be a particularly sensitive taxon, in that they show particularly strong responses to very low levels of sound. For example, Fig. 1 shows tracks of harbor porpoise Phocoena phocoena in British Columbia, tracked in control conditions and when exposed to an electronic pinger that made short sounds at a source level of $145 \mathrm{~dB}$ re $1 \mu \mathrm{Pa}$ (Culik et al. 2001). The porpoises avoided the pinger at a range of several hundred meters, corresponding to an exposure at the animal of about $100 \mathrm{~dB}$ re $1 \mu \mathrm{Pa}$.

Most of the experiments discussed to this point have been designed after preliminary observational data suggested a link between a particular stimulus and a response. Other controlled exposure studies have been designed to test whether there is a potential for risk even in the absence of evidence of a hazard. For this application, it is important to select responses that can be interpreted in terms of disruption of critical activities of the subjects. For example, one of the earliest such studies investigated the responses of gray whales Eschrichtius robustus migrating along the California coast to sounds associated with exploration and production of oil and gas. Since the primary behavior of the whales was migration, the response measure selected was deflection from migration to avoid the sound source. The migration provided a setting particularly well suited to the experimental design. During each migration season, whales only migrated south from the polar feeding ground to the tropical breeding grounds, or vice versa. This meant that each whale tracked as it swam from north to south past the sound source could be assumed to be a new subject for that season. Whales were dispersed enough that it was possible for observers on shore to follow individual groups of whales. Surveyor's theodolites could be used to pinpoint the location of the whales as they migrated. A ship moored in the center of the migration corridor projected sounds of industrial activities during experimental periods. Compared to control periods, there was a gap in tracks around the sound source during exposure periods. The whales avoided intermittent sounds of airguns and playback of continuous sounds of activities such as drilling or propulsion noise of vessels at about the same distance. However, the airguns were much louder than the playbacks of recorded sounds, and the levels of sound required to elicit avoidance were higher for airguns than for the other sounds. About $50 \%$ of the whales avoided exposure to continuous sounds, such as engine or drilling noise at a received level of $120 \mathrm{~dB}$ re $1 \mu \mathrm{Pa}$, while $50 \%$ avoidance of impulses from airguns required a received level of $170 \mathrm{~dB}$ re $1 \mu \mathrm{Pa}$ (Malme et al. 1983, 1984). This study took advantage of the highly oriented behavior of migrating gray whales. A similar study of gray whales during the feeding season did not yield such strong evidence for a response, in part because the behavior of foraging whales appeared more variable, in large measure because of our ignorance of the underlying factors influencing the whales' decisions about foraging (Malme et al. 1988).

Note that similar playbacks to harbor porpoises (Culik et al. 2001) showed stronger avoidance reactions at considerably lower received levels. There is considerable variability between species and between behavioral contexts. While it would be very difficult to study responses of all species in all contexts, extrapolation of results should be carried out with caution. This concern highlights the importance of attending to unexpected impacts, such as the atypical mass strandings of beaked whales such as Ziphius cavirostris or Mesoplodon densirostris during sonar exercises. Beaked whales are among the most difficult species to study, but the stranding-sonar link emphasizes the need for such studies, as beaked whales may well not receive sufficient protection if effects are extrapolated from other species.

Another example of a precautionary study involves experiments to test potential effects of a new lowfrequency active (LFA) sonar. These experiments were designed before the LFA sonar became operational. No incidents had been observed during sonar testing, indicating that LFA sonar disturbed marine life, but concerns had been raised about the effects of the LFA sonar on baleen whales because the communication calls of endangered baleen whales overlapped with the frequency range of the sonar. Most baleen whale species have a strong annual cycle, feeding in polar waters during the summer, migrating to more equatorial breeding grounds where they winter, followed by a spring migration back to the feeding grounds. The experiments on the effects of the sonar were designed to evaluate impacts of the sonar on all 3 seasons of the baleen whales' year, and response parameters were selected to be appropriate to study disruption of activities critical for the goal of behavior for each season.

Croll et al. (2001) examined the distribution, abundance, and vocal behavior of balaenopterid whales before, during, and after broadcast periods of LFA sonar signals during their summer feeding season off southern California. They mapped the distribution of whale prey, as well as the sound fields from the sonar playbacks, and concluded that, while whale sighting rates were too low for statistical comparisons, they did not appear to be related to the sound field generated by the sonar, but instead appeared to be linked to food abundance. This conclusion must be tempered by the caveat that little is known about the underlying factors 


\section{Tracks of Migrating Gray Whales \\ During Low Frequency Sonar Playback}
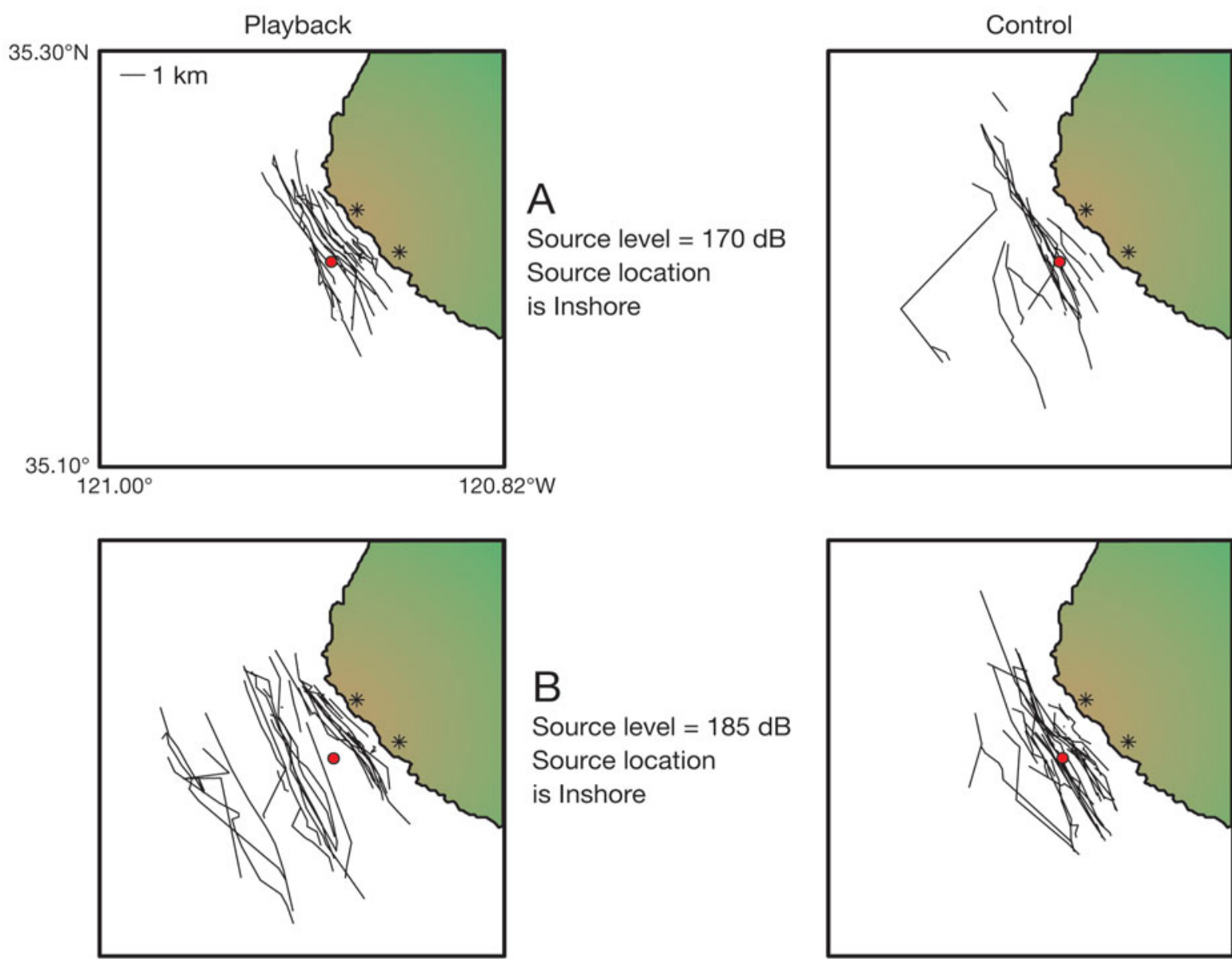

B

Source level $=185 \mathrm{~dB}$

Source location

is Inshore

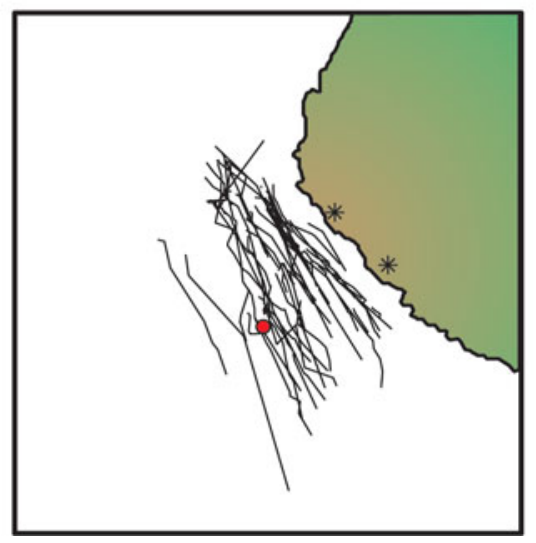

C

Source level $=185 \mathrm{~dB}$

Source location

is Offshore
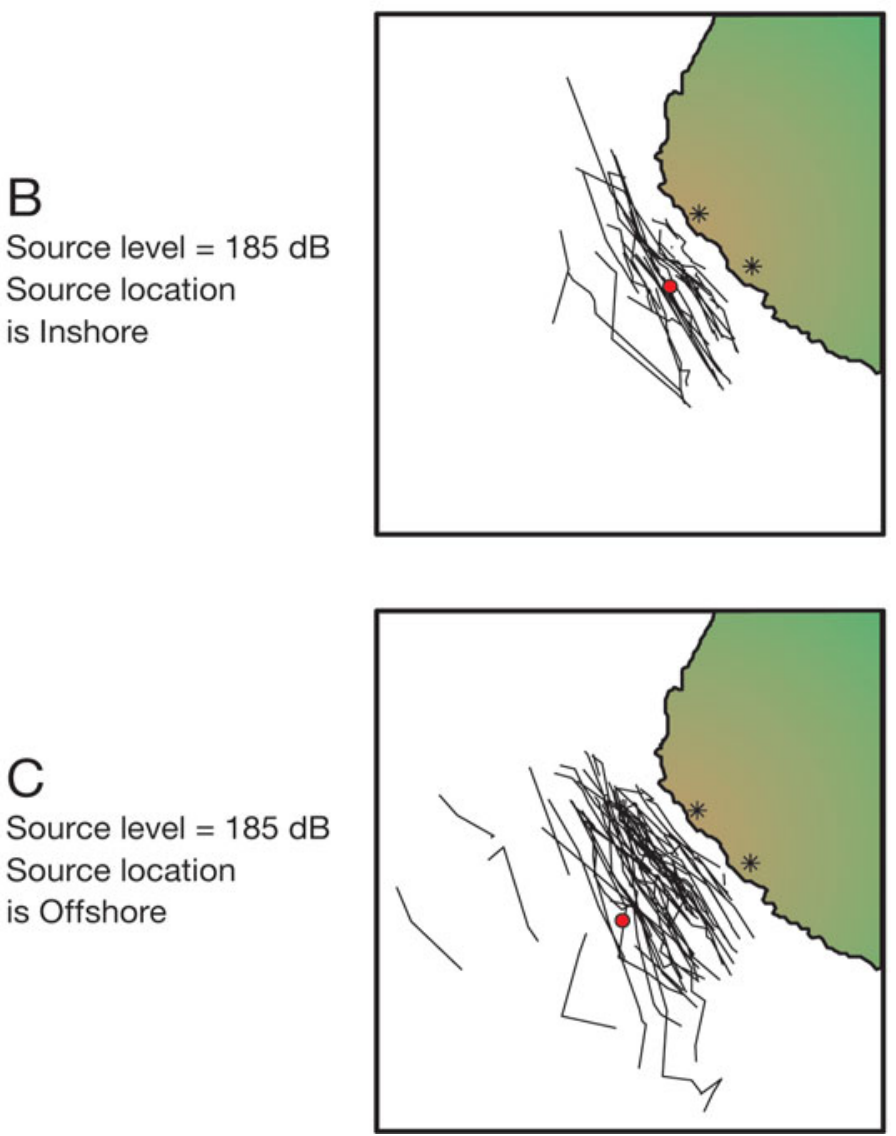

Fig. 2. Eschrichtius robustus. Tracks of gray whales migrating south past the central California coast near Point Buchon. Whales were tracked from the 2 shore stations indicated by the asterisks onshore. Tracks in the left column were made during playbacks of low-frequency active sonar sounds from a ship moored in the position indicated by the red circle; tracks in the right column were made from matching control intervals when the ship was in the same place, but not transmitting. The source was inshore near the center of the migration corridor for the top 2 rows; the source level for playback was $170 \mathrm{~dB}$ re $1 \mu \mathrm{Pa}$ at $1 \mathrm{~m}$ for upper panels (A) and $185 \mathrm{~dB}$ re $1 \mu \mathrm{Pa}$ at $1 \mathrm{~m}$ for the middle panels (B). Gaps in tracks are evident for inshore playbacks compared to controls, especially just downstream of the source. The gap disappears when the sound source is placed farther offshore (operated at the same $185 \mathrm{~dB}$ source level; C) 
driving movements of foraging whales, and the variability in their foraging behavior may obscure reactions to sound. Migration behavior allows for a more powerful test of avoidance. The LFA sonar has signals long enough and loud enough that, based upon the results of the Malme et al. $(1983,1984)$ studies, it was reasonable to predict that migrating gray whales might show avoidance at ranges of tens of kilometers, sufficient to have the potential to disrupt migration. This concern motivated an experiment using the same playback design developed by Malme et al. $(1983,1984)$ to evaluate the impact of the LFA sonar on gray whales migrating past the California coast. The experiment started with source levels much lower than the sonar and only gradually increased the source level once avoidance analysis suggested that the responses observed were safe. This design proved that when the sound source was moored in the middle of the migration corridor, whales increased their avoidance distance with increased source level. Fig. 2A shows playback and control tracks when the sound source broadcast LFA signals inshore at a source level of $170 \mathrm{~dB}$ re $1 \mu \mathrm{Pa}$, and Fig. 2B shows tracks from the same playback stimulus, but with a source level of $185 \mathrm{~dB}$ re $1 \mu \mathrm{Pa}$. Comparing the 2 playback panels, the gap in tracks near the sound source (red circle) was larger for the higher source level. The received levels that caused avoidance can be pooled across all the source levels, indicating that about half the whales avoided exposures of $\sim 140 \mathrm{~dB}$ re $1 \mu \mathrm{Pa}$ (Buck \& Tyack 2000). One of the control conditions used for the present study was to place the sound source offshore of the migration corridor, in a position more realistic for a sonar that is typically operated far offshore in deep water. As can be seen in Fig. 2C, when the sound source was moved offshore, the avoidance response disappeared, even for whales exposed to levels well above those that caused avoidance inshore. This variation in responsiveness caused by changing the context of exposure is commonly observed in behavioral ecology and, in this case, suggests a mitigation measure of requiring the sonar to be operated offshore of the migration corridor.

The third study on the effects of LFA sonar on whales involved studying the responses of male humpback whales Megaptera novaeangliae singing in Hawaiian waters during the winter breeding season. The baseline behavior of singers has already been well characterized in this environment (Tyack 1981, 1982, Payne et al. 1983, Tyack \& Whitehead 1983). This was the study that yielded the result already discussed that humpback whales can compensate for the sonar sound by increasing the redundancy of their song (Miller et al. 2000). While some whales were also observed to stop singing during sonar playback, cessation of singing is a common behavior in baseline observations, and the whales started singing after short enough intervals to reduce concern about disruption of breeding behavior.

\section{Responses of sperm whales to seismic surveys}

As exploration for and production of offshore oil and gas pushes into the deep ocean, there is increasing concern about the potential impact of seismic exploration on sperm whales Physeter macrocephalus, which is listed by the United States as an endangered species. This concern led the United States Minerals Management Service, in conjunction with the oil and gas industry, to fund a Sperm Whale Seismic Study (SWSS) to investigate effects of seismic surveys on sperm whales in the Gulf of Mexico. This study was a broad research program examining the genetic structure of sperm whale populations, their distribution in the Gulf of Mexico and how this was affected by oceanographic parameters, movement patterns of sperm whales in the gulf, and effects of seismic surveys on the behavior of sperm whales. The effects studies focused on using tags to monitor the behavior of whales. One study used satellite tags to monitor longterm movements of whales and to compare these to the locations of seismic surveys. The other study used behavior-and-sound recording tags called Dtags to monitor the behavior of whales before, during, and after CEEs of sounds of airguns used for seismic surveys. Sperm whales in the Gulf of Mexico spend about $75 \%$ of their time on deep foraging dives (Watwood et al. 2006). For this reason, foraging behavior was selected as the primary response variable for the controlled exposures. Sperm whales echolocate to find their prey during foraging dives. Each time a sperm whale attempts to capture a prey item, it accelerates the echolocation clicks into a sound called a buzz (Miller et al. 2004a). These buzzes are recorded on the Dtag and can be used as a proxy for foraging rates. The Dtag also uses 3-axis magnetometers and accelerometers to record changes in the orientation and movement of the tagged whale (Johnson \& Tyack 2003). Fluctuations in the pitch angle of the whale was used to record the fluking pattern of the whale as it swims, and this was used to estimate the relative locomotion effort for each tagged whale (Miller et al. 2004b). The experiment using the Dtags was thus designed to evaluate changes in the foraging rate and locomotion effort during foraging for whales before, during, and after exposure to airgun sounds.

The level of airgun exposure at the whale was preplanned as part of the experimental design. The plan called for several phases of exposure, starting at levels 
below those currently regulated, with the goal level only to be increased after analysis suggested no effect at the lower levels. The sound level at the whale was controlled in real time using propagation modeling to predict exposure, and the actual received level at the whale was recorded on the Dtag for later analysis. The stimulus used for sound exposure was the sound of an actual commercial airgun array. This was considerably more expensive and complicated than using a single airgun, but the sponsors of the study were adamant about using the actual source involved in seismic surveys. It turned out that while geophysicists know much about the sound reflected from strata below the seafloor, surprisingly little is known about the sound field produced in the water column by an array of airguns. One of the first important results of this study was the demonstration that airgun arrays transmit considerably more high-frequency energy than originally thought (DeRuiter et al. 2006, Madsen et al. 2006). In addition, under some propagation conditions found in the Gulf of Mexico, the received levels of sound from the airgun array were higher than generally predicted. The National Marine Fisheries Service, which is the regulator in the United States for effects of human activities on cetaceans limits exposures of cetaceans to airgun pulses based on a 'not to exceed' level of $180 \mathrm{~dB}$ re $1 \mu \mathrm{Pa}$, above which there is concern about possible risk of injury, and the regulator requires that permitholders estimate the number of animals that might have been harassed by exposures $>160 \mathrm{~dB}$ re $1 \mu \mathrm{Pa}$ (Allen 2004). Acoustic measurements (Tolstoy et al. 2004) showed that the ranges used to estimate these exposure levels were not conservative enough in some settings.

During the first 2 of the planned 3 yr of CEE cruises, the SWSS project conducted CEEs with 8 Dtagged sperm whales in the Gulf of Mexico. One of the whales was resting at the surface during playback and waited until minutes after playback to start foraging (Miller et al. 2009). All of the 7 whales that foraged during playback showed reduced locomotion effort judged by the pitch changes associated with swimming movements. Statistical analysis of locomotion effort during and

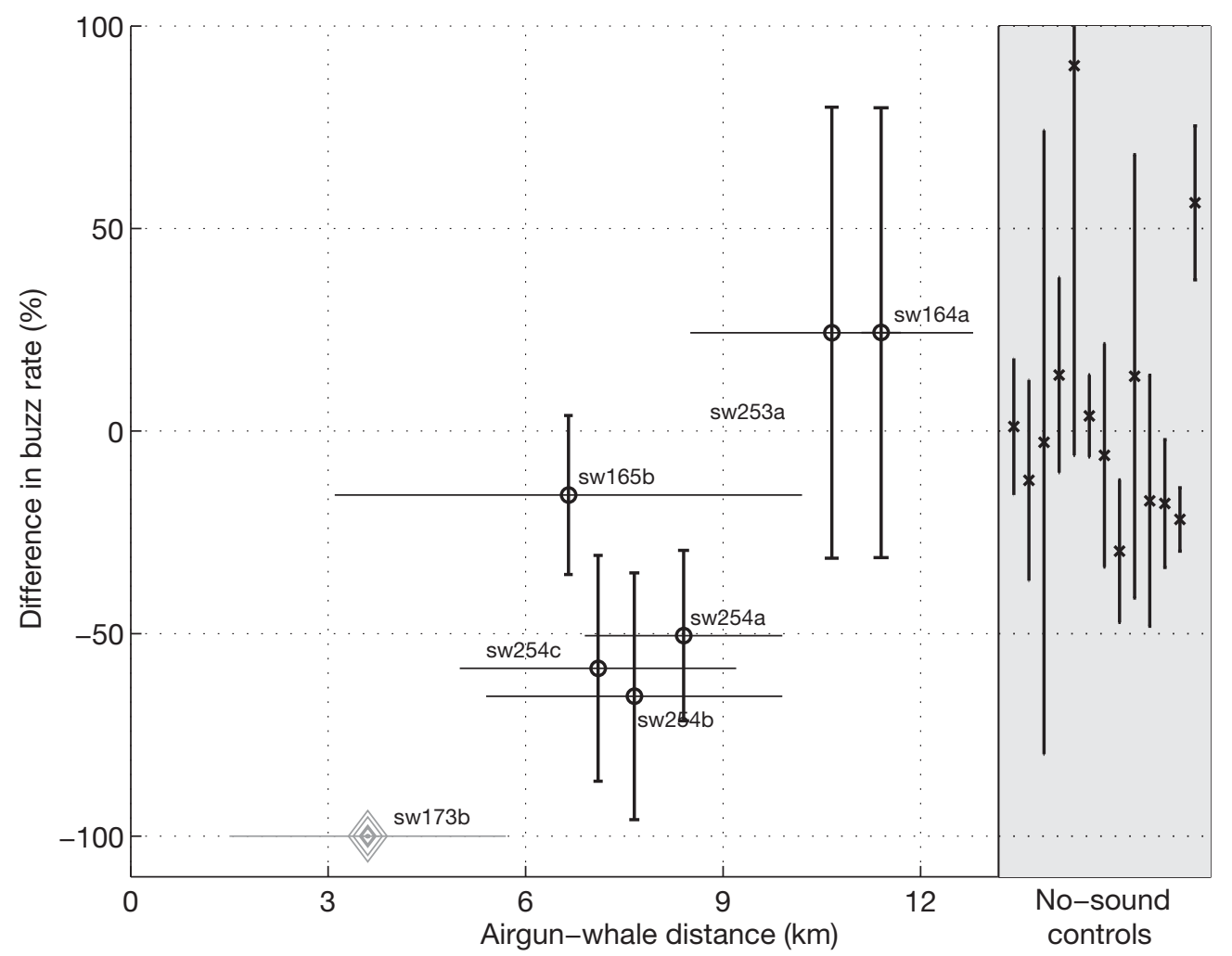

Fig. 3. Physeter macrocephalus. Changes in foraging behavior of 7 of 8 sperm whales exposed to airguns. The eighth sperm whale is not included as it was not tracked, so the distance between the airguns to the whale was not known. The rate of buzzes produced by each tagged whale is used as a proxy for foraging rate, as buzzes are thought to represent attempts to capture prey. The difference in buzz rates during airgun exposure compared to after exposure is plotted as a function of distance to the seismic vessel (left panel). The horizontal bars indicate the range of distances during airgun exposure; the vertical bars indicate the standard error of difference in buzz rate. The whale at $-100 \%$ marked in light grey stayed at the surface during the entire exposure and produced no buzzes as it conducted no deep foraging dives. The shaded section (right panel) compares buzz rates of sperm whales not exposed to airguns during and after no-sound control periods that mimicked the timing of exposure and post-exposure conditions in the exposure experiments 
after exposure demonstrated that their locomotion effort was reduced by an average of $6 \%$ during exposure ( $p=0.014$; Miller et al. 2009). Fig. 3 shows that the buzz rate of the whales varied as a function of range from the whale to the sound source. This reduction averaged $19 \%$ during exposure, but the aggregate effect for all whales was not statistically significant given the small sample size $(p=0.14)$. DeRuiter (2008) developed a statistical technique that allowed analysis of the significance of response for each individual whale. This analysis determined significant reductions in foraging for 2 of the 7 whales ( $p=0.025$ and 0.04 ); this analysis estimated the significance of the aggregate response from all whales at $\mathrm{p}=0.046$.

Large-scale CEEs are so difficult and expensive to conduct that they will often have limited sample sizes. These kinds of experiments will never match the sample sizes envisioned when statistical analyses were first developed as part of experimental designs. For example, Fisher (1935) designed agricultural experiments where one could plant any number of seeds in different conditions and measure responses. Modern work with laboratory animals may involve more cost per individual, but many experiments with laboratory animals can involve 1000s of subjects. Some species or stocks of most concern for studying effects of noise are so endangered that the entire species only numbers in the 100s. Even where the risk to each subject is thought to be low, work with threatened populations should limit exposure and sample size as much as possible. Where the individual animal is the unit of analysis, these issues fundamentally limit the sample size available. On the other hand, CEEs such as the one just described obtain large amounts of detailed exposure and response data from each subject. All of these issues emphasize the need to develop statistical methods designed to maximize the statistical power obtained from each subject. This approach suggests experimental designs that define precisely how animals respond to sound, and that can measure the exposure required to elicit a response from each individual, but the complexity of animal behavior complicates the kind of dose-response approach used in toxicological studies. The responsiveness of an animal to sound may depend upon its behavioral state, motivational context, history of exposure, condition and ecological circumstances, age, and sex, as well as upon the dosage of sound (Wartzok et al. 2003). Any results obtained from carefully designed experiments should be validated with exposures that are more similar to those generated by the activities that may cause the problem. It is also important to understand the strategic choices available to the subject. For example, an animal may not show avoidance behavior if it does not have alternate habitat available (Gill et al. 2001).
When studying foraging behavior, it is important to recognize that broader ecosystem effects may influence the results obtained. In the case of foraging sperm whales, Miller et al. (2009) could not discriminate whether the airguns affected only the feeding whales or whether they also affected the distribution and behavior of the prey. Engås et al. (1996) studied the distribution of fish near a seismic survey and found that the abundance of haddock and cod estimated by catch rates and echosounders was reduced by $45 \%$ or more. While these fish species differ from the prey of sperm whales in the Gulf of Mexico, the results highlight the need for integrated study of predator and prey, along with sensitivity for other ecosystem effects. The methods most suitable for mapping the prey field around foraging marine mammals use precision sonars to detect the prey. Understanding both the distribution of prey and their potential reactions to sound are critical for studying the effects of anthropogenic sound on foraging, but it will be important to ensure that these sonars themselves do not affect either the marine mammal subjects or their prey.

The studies described here tend to be in the realm of applied research, designed to predict the effects of human activities; few sources fund basic research of this nature. There is often a requirement that the 'polluters pay' for studying the impact of their activities, but regulatory agencies or conservation and animal welfare groups may also support research on effects of human activities. In general, the more diverse the sources of funding support, with the more points of view represented, the more robust and accepted the results of the overall research effort will be. However, just as in the case of 'tobacco science' (Marshall 1987) or drug studies supported by drug companies, there is a danger that the research may be manipulated by special interests. For example, Rising et al. (2008) reported that there is a bias in publication for studies of new drugs funded by the drug industry, whereby studies with results that favor the industry are more likely to be published than others. There is a risk of similar bias in the funding of conservation research. A case in point involves the $3 \mathrm{yr}$ research effort to study the responses of tagged sperm whales to the airguns used for seismic surveys. By the second year of this field work, as discussed above, potential responses of sperm whales were observed at exposure levels well below those currently regulated, and the study also measured more energy $>1 \mathrm{kHz}$ than conceded by the seismic industry (DeRuiter et al. 2006). Calibration measurements of sounds from an airgun array made during this period also showed that, under some acoustic propagation conditions, the stand-off range used by the United States regulator to prevent exposure above specified sound levels did not actually protect animals from 
exposures above the regulated levels (Tolstoy et al. 2004). After the second of 3 planned years of field work, even though there was no reduction in funding for the overall program, the playback component of the third year of field work was cancelled, reducing the power of the project to test for effects. According to the original research plan, the protocol for this third year called for continuing to test exposures at the levels at which effects had been observed before testing a higher range of exposures. Sponsors brought up concern that the research did not include higher exposure levels near $180 \mathrm{~dB}$ re $1 \mu \mathrm{Pa}$. It is understandable why sponsors seeking regulatory relief would not be enthusiastic about studying effects at exposures below those regulated, but, from a scientific perspective, it did not make sense to move to a new exposure region just as the small sample size for the lower exposures was suggesting an effect. The lack of transparency in the decision-making process makes it difficult to uncover the motives for the premature cancellation of the playback study, but the end result of the process seems to have created a similar risk of bias as that identified for industry-supported studies of drugs, whereby the industry may fund several projects to study the effects of a drug, but then only provide follow-up support for publication to those that report more positive effects and/or fewer adverse ones. If funders with special interests are able to reduce the probability of publication for research projects with results that they perceive as adverse to their interests, then the body of research papers resulting from the research may distort the scientific evidence and will not accurately reflect the risk.

\section{Selection of subjects}

If research is designed to protect animals from the effects of human sounds, then it is important to include in the study subjects of species, age, and sex classes thought to be most vulnerable. McEwen \& Wingfield (2003) also point out that each age/sex class of a species may be most vulnerable during a particular season at a particular site. These points may seem obvious, but it can be difficult to identify the most vulnerable subjects with certainty. If adequate information is not available to predict vulnerability, then a large set of subjects from different age/sex classes may be required. If the most vulnerable animals are thought to be dependent young, then there may be regulatory obstacles to selection of the appropriate subjects. For example, in the United States, the National Marine Fisheries Service Office of Protected Resources is responsible for issuing permits for this kind of research with cetaceans and pinnipeds. For some species, their permits prohibit playbacks to young animals. In this case, policies for protecting these species will have to be based on studying older, independent, and likely less vulnerable animals. Where young are routinely exposed to these sounds, the prohibition on studying responses of young may result in policies that do not provide adequate protection for them.

\section{Selection of stimuli and mode of presentation}

For studies on the effect of specific anthropogenic sounds on marine mammals, there is often pressure to use exactly the same source and stimuli for experiments as that used in normal applications. This choice reduces uncertainty about whether the results from the experiment can appropriately be applied in situ. However, some of the sources are of concern because of their high intensity. Sources such as naval sonars and airgun arrays used for seismic surveys require large, specialized vessels that are very expensive. Even if they can be made available for research purposes, it may be particularly difficult for the experimenter to fully control use of the source or to have access for long enough to attain an adequate sample size. Devices that use arrays of sound sources to direct the sound can produce highly complex sound fields that may also reduce the ability of the experimenter to predict and control the sound at the subject animal. Animal welfare considerations often call for reducing the number of animals affected and for refining the experimental design to reduce the potential distress. One way to reduce the number of animals that might be affected involves using a sound source that projects most of the sound energy in the direction of the subject, while reducing exposure in other directions. In practice, there will often be a tradeoff between intense arrays of sources capable of directionality and smaller, lessintense sources that are less directional.

If there is any potential for avoidance reactions, it is important when searching for a new subject to make sure that prior transmissions could not bias the population being sampled. For example, if playbacks are conducted day after day in the habitat of a resident population, the most sensitive animals may move away, leaving the least sensitive to be tested. These issues lead most CEEs to differ from operational use of a source by transmitting much less frequently, and reducing the possibility of the bias listed above by measures such as moving away from the impact zone of a playback before starting the next playback.

The behavior of different individuals or groups differs enough that it is important to obtain baseline behavioral data from each individual animal or interacting group, ideally before exposure. Especially for 
experiments designed to test for differential responsiveness to several stimuli, a powerful design involves playing a series of stimuli to the same subject or group in the same behavioral context. Using a sequence of exposures raises concerns that the subject may not have fully returned to baseline before the second playback, or that responses may differ between the first and second exposure as a function of the novelty of the playback, habituation, or sensitization. One way to control for these order effects is to vary the order of presentation of the different stimuli to different subjects, in a balanced design.

Given all of the concerns raised above, when it is feasible to use the actual source and stimulus of concern and an adequate sample size is achievable, that selection produces the most relevant results. However, in many cases the use of a different source may simplify or improve the experimental design. In these cases, it is often better to optimize the source, stimuli, and mode of presentation for the cleanest experiment, and to complement the experiment with observational study of the actual source as used in normal practice (Richardson et al. 1995). This combination will often yield the most powerful ability to predict the effects of sound on marine animals. If possible, added power for observational studies can be derived from selection of a control site with environmental and social factors matching those at the exposure site. Parallel observations of control and exposure sites can help test for effects that may be caused by factors other than acoustic exposure, although it can be difficult to match sites for all revelant parameters.

\section{CONCLUSIONS}

I have discussed experiments that were successful, to varying degrees, in relating the behavioral responses of marine organisms to specific exposures to sound. We can conclude that carefully controlled experiments are generally most efficient when they diverge somewhat from the exposures of concern. Rather than compromising experimental design in favor of the realism of exposure, it may be more efficient to plan a research program that includes both carefully controlled experiments and realistic observational studies of the exposure to the actual activities of concern. In some cases, such as the atypical mass strandings of beaked whales, opportunistic observations can identify an unexpected problem. In this case, experiments can be used to test what levels of exposure to which signals pose what risks to which species. In other cases, such as the study of airgun effects on sperm whales, carefully controlled experiments can reveal an effect that was completely unexpected. In this case, once the response of concern has been identified, this information can help with the design of observational studies to monitor the responses of whales near actual seismic surveys. Just as short-term behavior-and-sound recording tags have facilitated experiments, so development of longer term tags and acoustic monitoring devices capable of recording selected data on acoustic exposures and behavioral responses over time scales relevant for normal operations of sound sources will facilitate observational monitoring of effects.

Controlled experiments to study the effects of sound on marine organisms have distinct benefits and problems. Protection of marine life from adverse impacts of anthropogenic sound will require a research program that balances careful experiments to detect specific responses and the exposures required to elicit them with observational studies designed to have a high statistical power for detecting the effects of actual soundproducing activities. Perhaps the largest remaining challenge involves estimating long-term populationlevel effects of human impacts on marine life. Some hard-to-detect effects such as the failure of a female to find a male during the breeding season may, if compounded many times, have more significant adverse effects for marine populations than more dramatic responses of single individuals.

Acknowledgements. P.T. thanks the Guest Editor for this paper, Brandon Southall, and the 4 anonymous reviewers of the manuscript for excellent comments and for suggesting useful references. The research conducted by P.T. and colleagues that is described in this paper was funded by the US Chief of Naval Operations Submarine Warfare Division (Undersea Surveillance), the Industry Research Funding Coalition, the Environmental Readiness Division of the US Navy, the Joint Industry Program on Sound and Marine Life of the International Association of Oil and Gas Producers, the US Minerals Management Service, the US National Oceanic and Atmospheric Administration (National Marine Fisheries Service, Office of Science and Technology), the US Office of Naval Research, and the US Strategic Environmental Research and Development Program.

\section{LITERATURE CITED}

Allen LK (2004) Taking and importing marine mammals; taking marine mammals incidental to conducting oil and gas exploration activities in the Gulf of Mexico. Federal Register 69(222):67535-67539

Allen MC, Read AJ (2000) Habitat selection of foraging bottlenose dolphins in relation to boat density near Clearwater, Florida. Mar Mamm Sci 16:815-824

Allen T, Finkbeiner SL, Johnson DH (2004) Comparison of detection rates of breeding marsh birds in passive and playback surveys at Lacreek National Wildlife Refuge, South Dakota. Waterbirds 27:277-281

$\mathrm{Au}$ WWL (1993) The sonar of dolphins. Springer, Berlin

> Bejder L, Samuels A, Whitehead H, Gales N and others (2006) Decline in relative abundance of bottlenose dolphins exposed to long-term disturbance. Conserv Biol 20: 1791-1798 
Best PB (2008) Nineteenth-century evidence for the Golfo de Panama as a migratory destination for southern humpback whales, including the first mention of singing. Mar Mamm Sci 24:737-742

Bryant PJ, Lafferty CM, Lafferty SK (1984) Reoccupation of Laguna Guerrero Negro, Baja California, Mexico, by gray whales. In: Jones ML, Swartz SL, Leatherwood S (eds) The gray whale, Eschrichtius robustus. Academic Press, Orlando, FL, p 375-387

Buck JR, Tyack PL (2000) Responses of gray whales to low frequency sounds. J Acoust Soc Am 107:2774

- Clark CW, Clark JM (1980) Sound playback experiments with southern right whales (Eubalaena australis). Science 207: 663-665

Cox TM, Ragen TJ, Read AJ, Vos E and others (2006) Understanding the impacts of anthropogenic sound on beaked whales. J Cetacean Res Manag 7:177-187

Croll DA, Clark CW, Calambokidis J, Ellison WT, Tershy B (2001) Effect of anthropogenic low-frequency noise on the foraging ecology of Balaenoptera whales. Anim Conserv $4: 13-27$

Culik BM, Koschinski S, Tregenza N, Ellis GM (2001) Reactions of harbor porpoises Phocoena phocoena and herring Clupea harengus to acoustic alarms. Mar Ecol Prog Ser 211:255-260

Cummings WC, Thompson PO (1971) Gray whales, Eschrichtius robustus, avoid the underwater sounds of killer whales, Orcinus orca. Fish Bull (Wash DC) 69: 525-530

D'Amico A (1998) Summary record, SACLANTCEN bioacoustics panel. Saclant Undersea Research Centre, La Spezia

DeRuiter SL (2008) Quantitative analysis of echolocationbased foraging by harbor porpoises and sperm whales, including effects of noise and acoustic propagation. $\mathrm{PhD}$ dissertation, Woods Hole Oceanographic Institution, Woods Hole, MA

> DeRuiter SL, Tyack PL, Lin YT, Newhall AE, Lynch JF, Miller PJO (2006) Modeling acoustic propagation of airgun array pulses recorded on tagged sperm whales (Physeter macrocephalus). J Acoust Soc Am 120:4100-4114

Engås A, Løkkeborg S, Ona E, Soldal AV (1996) Effects of seismic shooting on local abundance and catch rates of cod (Gadus morhua) and haddock (Melanogrammus aeglefinus). Can J Fish Aquat Sci 53:2238-2249

Evans DL, England GR (2001) Joint interim report, Bahamas marine mammal stranding, event of 15-16 March 2000. US Department of Commerce and Secretary of the Navy, Washington, DC

Fish JF, Vania JS (1971) Killer whale, Orcinus orca, sounds repel white whales, Delphinapterus leucas. Fish Bull (Wash DC) 69:531-535

Fisher RA (1935) The design of experiments. Oliver and Boyd, Edinburgh

Frantzis A (1998) Does acoustic testing strand whales? Nature 392:29

Friedman N (1989) The Naval Institute guide to world naval weapons systems. Naval Institute Press, Annapolis, MD

Garner RL (1892) Speech of monkeys. Webster, New York

Gibbs JP, Melvin SM (1993) Call-response surveys for monitoring breeding waterbirds. J Wildl Manag 57:27-34

Gill JA, Norris K, Sutherland WJ (2001) Why behavioural responses may not reflect the population consequences of human disturbance. Biol Conserv 97:265-268

Hohn AA, Rotstein DS, Harms CA, Southall BL (2006) Report on marine mammal unusual mortality event UMESE0501Sp: multispecies mass stranding of pilot whales (Globicephala macrorhynchus), minke whale (Balaen- optera acutorostrata), and dwarf sperm whales (Kogia sima) in North Carolina on 15-16 January 2005. NOAA Tech Memo NMFS-SEFSC-537, National Marine Fisheries Service, Silver Spring, MD

Janik VM, Thompson PM (1996) Changes in surfacing patterns of bottlenose dolphins in response to boat traffic. Mar Mamm Sci 12:597-602

Johnson MP, Tyack PL (2003) A digital acoustic recording tag for measuring the response of wild marine mammals to sound. IEEE J Oceanic Eng 28:3-12

> Johnson MP, Madsen PT, Zimmer WMX, Aguilar de Soto N, Tyack PL (2004) Beaked whales echolocate on prey. Proc R Soc Lond B Biol Sci 271:383-386

> Kroodsma DE, Byers BE, Goodale E, Johnson S, Liu WC (2001) Pseudoreplication in playback experiments, revisited a decade later. Anim Behav 61:1029-1033

Lorenz K (1939) Vergleichende Verhaltensforschung. Zool Anz 12:69-102

Madsen PT, Johnson M, Aguilar de Soto N, Zimmer WMX, Tyack PL (2005) Biosonar performance of foraging beaked whales (Mesoplodon densirostris). J Exp Biol 208: 181-194

Madsen PT, Johnson M, Miller P, Aguilar de Soto N, Tyack P (2006) Quantitative measures of airgun pulses impinging on sperm whales using onboard tags and controlled exposures. J Acoust Soc Am 120:2366-2379

Malakoff D (2002) Suit ties whale deaths to research cruise. Science 298:722-723

Malme CI, Miles PR, Clark CW, Tyack P, Bird JE (1983) Investigations of the potential effects of underwater noise from petroleum industry activities on migrating gray whale behavior. Bolt Beranek and Newman Report No. 5366 submitted to Minerals Management Service, US Dept of the Interior, Anchorage, AK. Available at: www.mms.gov/ alaska/reports/1980rpts/akpubs80s.htm

Malme CI, Miles PR, Clark CW, Tyack P, Bird JE (1984) Investigations of the potential effects of underwater noise from petroleum industry activities on migrating gray whale behavior. Phase II: January 1984 migration. Bolt Beranek and Newman Report No. 5586 submitted to Minerals Management Service, US Dept of the Interior, Anchorage, AK. Available at: www.mms.gov/alaska/reports/1980rpts/ akpubs80s.htm

Malme CI, Wursig B, Bird JE, Tyack PL (1988) Observations of feeding gray whale responses to controlled industrial noise exposure. In: Sackinger WM, Jefferies MO, Imm JL, Treacy SD (eds) Port and ocean engineering under arctic conditions. University of Alaska, Fairbanks, AK, p 55-73

Marshall E (1987) Tobacco science wars. Science 236:250-251

McEwen BS, Wingfield JC (2003) The concept of allostasis in biology and biomedicine. Horm Behav 43:2-15

McGregor PK (1992) Playback and studies of animal communication. Plenum Press, New York

Miller PJO, Biassoni N, Samuels A, Tyack PL (2000) Whale songs lengthen in response to sonar. Nature 405:903

Miller PJO, Johnson MP, Tyack PL (2004a) Sperm whale behaviour indicates the use of echolocation click buzzes 'creaks' in prey capture. Proc R Soc Lond B Biol Sci 271: 2239-2247

Miller PJO, Johnson MP, Tyack PL, Terray EA (2004b) Swimming gaits, passive drag and buoyancy of diving sperm whales Physeter macrocephalus. J Exp Biol 207: 1953-1967

Miller PJO, Johnson MP, Madsen PT, Biassoni N, Quero ME, Tyack PL (2009) Using at-sea experiments to study the effects of airguns on the foraging behaviour of sperm whales in the Gulf of Mexico. Deep-Sea Res 56:1168-1181 
Morton AB, Symonds HK (2002) Displacement of Orcinus orca (L.) by high amplitude sound in British Columbia, Canada. ICES J Mar Sci 59:71-80

Myrberg A (1978) Ocean noise and the behavior of marine animals: relationships and implications. In: Fletcher JL, Busnel RG (eds) Effects of noise on wildlife. Academic Press, New York, NY, p 169-208

Myrberg A (1980) Fish bio-acoustics: its relevance to the 'not so silent world'. Environ Biol Fishes 5:297-304

Pauly D, Christensen V, Dalsgaard J, Froese R, Torres F Jr (1998) Fishing down marine food webs. Science 279: 860-863

Payne R, Webb D (1971) Orientation by means of long range acoustic signalling in baleen whales. Ann NY Acad Sci 188:110-141

Payne KB, Tyack P, Payne RS (1983) Progressive changes in the songs of humpback whales. In: Payne RS (ed) Communication and behavior of whales. AAAS Selected Symposia Series, Westview Press, Boulder, CO, p 9-59

Richardson WJ, Wursig B, Greene CR Jr (1986) Reactions of bowhead whales, Balaena mysticetus, to seismic exploration in the Canadian Beaufort Sea. J Acoust Soc Am 79: $1117-1128$

Richardson WJ, Greene CR Jr, Malme CI, Thomson DH (1995) Marine mammals and noise. Academic Press, San Diego, CA

Rising K, Bacchetti P, Bero L (2008) Reporting bias in drug trials submitted to the Food and Drug Administration: review of publication and presentation. PLoS Med 5:e217

Roeder KD (1962) The behaviour of free flying moths in the presence of artificial ultrasonic pulses. Anim Behav 10: 300-304

Roman J, Palumbi SR (2003) Whales before whaling in the North Atlantic. Science 301:508-510

Schevill WE, Lawrence B (1949) Underwater listening to the white porpoise (Delphinapterus leucas). Science 109: 143-144

Southall BL, Braun R, Gulland FMD, Heard A, Baird R, Wilkin S, Rowles T (2006) Hawaiian melon-headed whale (Peponocephala electra) mass stranding event of July 3-4, 2004. NMFS-OPR-31, National Marine Fisheries Service, Silver Spring, MD

Spiesberger JL, Fristrup KM (1990) Passive localization of calling animals and sensing their acoustic environment using acoustic tomography. Am Nat 135:107-153

Taylor BL (1995) The reliability of using population viability analysis for risk classification of species. Conserv Biol 9: 551-558

Taylor BL, Gerrodette T (1993) The uses of statistical power in conservation biology: the vaquita and northern spotted owl. Conserv Biol 7:489-500

Submitted: October 15, 2008; Accepted: October 7, 2009
Tinbergen N (1948) Social releasers and the experimental method required for their study. Wilson Bull 60:6-52

Tinbergen N, Kruyt W (1938) Über die Orientierung des Bienenwolfes (Philanthus triangulum Fabr.). Z Vgl Physiol 25:292-334

Tolstoy M, Diebold JB, Webb SC, Bohnenstiehl DR, Chapp E, Holmes RC, Rawson M (2004) Broadband calibration of R/V Ewing seismic sources. Geophys Res Lett 31:L14310, doi:10.1029/2004GL020234

Tyack PL (1981) Interactions between singing Hawaiian humpback whales and conspecifics nearby. Behav Ecol Sociobiol 8:105-116

Tyack PL (1982) Humpback whales respond to sounds of their neighbors. PhD dissertation, The Rockefeller University, New York

Tyack PL (1983) Differential response of humpback whales, Megaptera novaeangliae, to playback of song or social sounds. Behav Ecol Sociobiol 13:49-55

Tyack PL (1998) Acoustic communication under the sea. In: Hopp SL, Owren MJ, Evans CS (eds) Animal acoustic communication. Springer, New York, p 163-220

Tyack P (2008) Implications for marine mammals of largescale changes in the marine acoustic environment. J Mammal 89:549-558

Tyack PL, Whitehead H (1983) Male competition in large groups of wintering humpback whales. Behaviour 83: 132-154

Tyack PL, Gordon J, Thompson D (2003) Controlled exposure experiments to determine the effects of noise on marine mammals. Mar Technol Soc J 37:41-53

Urick RJ (1983) Principles of underwater sound. Peninsula Publishing, Los Altos, CA

von Frisch K (1938) The sense of hearing in fish. Nature 141:8-11

Wartzok D, Popper AN, Gordon J, Merrill J (2003) Factors affecting the response of marine mammals to acoustic disturbance. Mar Technol Soc J 37:6-15

Watwood SL, Miller PJO, Johnson MP, Madsen PT, Tyack PL (2006) Deep-diving foraging behavior of sperm whales (Physeter macrocephalus). J Anim Ecol 75:814-825

Weeden JS, Falls JB (1959) Differential response of male ovenbirds to recorded songs of neighboring and more distant individuals. Auk 76:343-351

Winn HE, Marshall JA, Hazlett B (1964) Behavior, diel activities, and stimuli that elicit sound production and reactions to sounds in the longspine squirrelfish. Copeia 1964: 413-425

> Zimmer WMX, Tyack PL, Johnson MP, Madsen PT (2005) Three-dimensional beam pattern of regular sperm whale clicks confirms bent-horn hypothesis. J Acoust Soc Am 117:1473-1485

Proofs received from author(s): November 23, 2009 